\title{
Effect of passive finger exercises on grip strength and the ability to perform activities of daily living for older people with dementia: a I2-week randomized controlled trial
}

This article was published in the following Dove Press journal:

Clinical Interventions in Aging

\author{
Bingbing Liu' \\ Xueping Chen' \\ Yang $\mathrm{Li}^{\prime}$ \\ Hui Liu² \\ Shasha Guo ${ }^{2}$ \\ Ping $\mathrm{Yu}^{3}$
}

'Nursing Department, Qianjiang College, Hangzhou Normal University, Hangzhou, China; ${ }^{2}$ Medicine Department, Hangzhou Normal University, Hangzhou, China; ${ }^{3}$ School of Computing and Information Technology, Faculty of Engineering and Information Sciences, University of Wollongong, Wollongong, NSW, Australia
Correspondence: Xueping Chen Nursing Department, Qianjiang College, Hangzhou Normal University, No 16 Xuelin Street, Jianggan District, Hangzhou 310036, China

Tel +86 I37 774| 88I7

$\mathrm{Fax}+86$ 57। 28861972

Email65I386590@qq.com
Background: Dementia adds burden to society. As it is not curable, physical exercise activities are optimal to improve the physical strength and quality-of-life of people with dementia.

Aim: Design, implementation, and examination of a set of passive finger exercises and their effects on improving grip strength and activities of daily living (ADL) for older people with dementia.

Methods: Forty older people with dementia were recruited and randomly allocated into an experimental group and a control group, each with 20 people. The control group received routine nursing care. In addition to this, the experimental group received 25-minutes of passive finger exercises every day for 12 weeks. The health outcomes measured were grip strength and ADL, before and after the intervention. Grip strength was assessed by electrical hand muscle dynamometer. ADL were assessed with Barthel index.

Results: Although there was no effect on grip strength, passive finger exercises led to significant improvements in urinary control, defecation function, and overall ADL in comparison with the control group.

Implications for practice: Passive finger exercises can be integrated into physical exercise programs for older people with dementia to improve their urinary control, defecation function, and ADL.

Keywords: physical exercise, passive finger exercise, grip strength, urinary control, defecation, activities of daily living, ADL, dementia

\section{Plain language summary}

What is known on the subject?

- Incidence of dementia among older people is on the rise globally.

- Grip strength and abilities to perform ADL decrease with the progression of dementia.

- Physical exercise holds the key for improving the quality-of-life for people with dementia.

\section{What this paper adds to existing knowledge?}

- Older people with dementia demonstrated improvement in their abilities to control urination and defecation, and overall ADL after receiving the passive finger exercises.

What are the implications for practice?

- Passive finger exercises can improve control of urination and defecation, and overall ADL for older people with dementia.

- The method can be incorporated into physical exercise programs for older people in home or residential care settings. 


\section{Introduction}

With population aging, dementia has become one of the major causes of disability and dependency among older people in the world. It is estimated that between 5 and 8 people in every 100 people aged 60 years and over suffer from dementia. ${ }^{1}$ Another estimation is that currently there are 47 million people globally with dementia. This number is projected to reach 75 million by 2030 and almost triple by 2050 . The cause of dementia remains unclear, nor is there any specific and effective cure for it thus far. ${ }^{2}$ Therefore, it is recommended to focus its nursing intervention on activities that can delay disease progression and promote quality-of-life. ${ }^{3}$

The inability to perform activities of daily living (ADL) is one of the core symptoms of dementia and a pre-condition for its diagnosis. ${ }^{4}$ It also negatively affects the mood and quality-of-life of people with dementia and elevates the burden for their caregivers. ${ }^{5,6}$ The inability to perform ADL is also closely related to a loss of cognitive function, an indicator of the level of dementia. Therefore, the level of ADL is an important indicator of needs for professional care or institutional stay, and a component for the planning of nursing goals and actions to improve the quality-of-life for people with dementia. ${ }^{7}$ It is, thus, important to design interventions, such as physical activities, to maintain the ability to perform ADL for a person with dementia.

Grip strength is the total gripping force produced when clenching one hand. It is an important index of muscle strength. A minimum grip strength of $9 \mathrm{~kg}$ is required to perform the desirable hand functions. ${ }^{8,9}$ A decrease in grip strength will result in the reduction in self-care ability and quality-of-life; therefore, grip strength is important for the maintenance of ADL. Although it is known that grip strength and the ability to perform ADL both decrease with age and progression of dementia, there is limited knowledge about the relationship between grip strength and the specified ADL; being eating, bathing, or others.

Hand movement can improve hand functions, ${ }^{10}$ prevent or alleviate other diseases, eg, pain arising from rheumatoid arthritis. ${ }^{11}$ It can also stimulate brain function and reduce the extent of brain-related disorders, ${ }^{12-14}$ and enhance the learning ability of students with intellectual disabilities. ${ }^{15}$ Bragin and Bragin ${ }^{16}$ found that a set of exercises including hand and finger movements in one or both hands can help people with dementia to restore hand and finger mobility and coordination, and increase their attention, procedural memory and speed of recall.

Rehabilitation effects of a particular type of hand movement, finger movement, on people with mental disorders, such as various degrees of dementia, have been reported.
Nyberg et $\mathrm{al}^{14}$ found that finger tapping can stimulate the motor cortex in the brain. Finger exercises can also maintain or improve ADL in people with mild cognitive impairment or dementia ${ }^{17,18}$ and the ability of self-care and handling tools. These effects are achieved in combination with a pharmaceutical regimen. ${ }^{19} \mathrm{Wu}$ et $\mathrm{al}^{20}$ found improvement in ADL after providing special nursing care including finger exercises to older people with moderate Alzheimer's disease. Zhang et $\mathrm{al}^{21}$ conducted 6-month sequential training with the major components of finger exercises and ADL, and found an improvement in the ability to perform ADL and quality-of-life for people with dementia. According to $\mathrm{Lu},{ }^{22}$ massaging in hand meridian and finger exercises can stimulate the acupuncture points, which may reduce the speed of regression of ADL and grip strength. Lee and don $\mathrm{Kim}^{23}$ found that physical activity can improve cognitive function and ADLs in people with mild dementia.

Based on the above evidence, we believe that passive finger exercises can improve ADL through its effect on improvement in cognition or, as in people without dementia, via a general strengthening of physical strength, measured by grip strength. To the best of our knowledge, the effect of finger movement on grip strength for people with dementia has never been studied. As people with dementia may not be able to perform finger exercises independently or adequately to achieve an effective result, this study aims to design and implement a set of passive finger exercises that are tailored to their conditions and to evaluate the effects of the exercises on grip strength and ADL. We will test two hypotheses.

H1: Grip strength will be stronger for the participants who receive the passive finger exercises than those who do not.

$\mathrm{H} 2$ : Scores of ADL will be higher for the participants who receive the passive finger exercises than those who do not.

\section{Materials and methods \\ Research design}

A randomized controlled trial was undertaken for 12 weeks. The intervention was passive finger exercises provided by a researcher. The study was approved by the Ethics Committee of the College of Medicine, Hangzhou Normal University and was performed in accordance with the principles stated in the Declaration of Helsinki. ${ }^{24}$ Written informed consent was obtained from each participant's family member or guardian. Oral consent was also acquired from the participants.

\section{Sampling}

\section{Inclusion and exclusion criteria}

The inclusion criteria were (1) aged over 60 years; (2) diagnosis of dementia by medical doctors; (3) the fingers were 
intact, free from disease restricting hand movement; (4) maintaining visual and oral communication function; (5) no history of taking anti-dementia drugs; and (6) oral consent by the participant and written consent provided by a family member or guardian. The exclusion criteria were (1) failure of multiple organs; (2) upper limb pain, severe arthritis, neural disease, or cardiovascular disease inhibiting passive exercises of fingers; (3) unstable blood pressure and arrhythmia caused by hand force; (4) prescription of anti-dementia drugs; and (5) not giving consent for participation.

\section{Sample size calculation}

The statistical power and effect size were calculated using SPSS v17.0 software for Windows (Chinese version). We adopted the result from Zhang and Liu, ${ }^{25}$ because the population they studied is similar to ours. They suggested the average difference in a subject's MMSE to be 2.73 with a standard deviation (SD) of 3.15. Significant difference was determined if $P<0.05$. According to this, a sample size of 16 participants in each group was adequate with the significance level $(\alpha)$ set at 0.05 and test power $(1-\beta)$ at 0.80 (twosided). Assuming the attrition rate to be $25 \%, 20$ participants in each group would provide the adequate sample size.

\section{Participant recruitment}

Participants were recruited from Hangzhou Love Heart Older's Home with the agreement of the home's manager. We informed the older person, his or her family member or guardian about the aim and process of the research project if the person met the inclusion criteria. The person was recruited into the study only after written consent was given by the family member or guardian, and oral consent was acquired from the person.

\section{Randomization}

Fifty four people met the inclusion criteria. They all resided in two floors of one building; 24 people on the ground floor, 30 on the first floor. To avoid potential contamination, using a lottery method, the people who lived on the first floor were all allocated into the intervention group, those who lived on the ground floor entered the control group.

\section{Intervention}

Participants in both groups continued their normal daily life and received routine nursing care, such as assistance with ADL, medication, and guided walks. In addition, the experimental group received a passive finger exercise.

The passive finger exercise was provided by a researcher (BL) once a day to each participant for 12 weeks. A session lasted 25 minutes. In order to establish rapport with the participants and deliver the exercise at a flexible time suitable for them, BL lived in the same building, having meals together with the participants during the intervention period. BL chatted with and sought feedback while providing hand massage to the participants. This also avoided injury, stress, and boredom. A small "thank you" token of a handkerchief was awarded to each participant for cooperation at the conclusion of the program.

\section{Passive finger movement exercise}

In consultation with four relevant domain experts in nursing, rehabilitation, and Chinese traditional medicine, a passive finger movement exercise program was designed based on active finger exercises. Its aim was to improve the older people's ADL and quality-of-life. The program was delivered in eight steps to accommodate the characteristics of older people:

Step 1. Warming up (Figure 1A): Straighten the person's fingers, placing two palms towards each other. The therapist's two hands cover one hand of the participant, rubbing up and down to warm it up. Complete the movement for both palms.

Step 2. Bending and stretching fingers (Figure 1B): Hold the palm of the left hand of the person, facing it upward, placing the back on the therapist's left palm. Then stretch and bend each finger, one-by-one, with gentle pressure.

Step 3. Pressing and pulling out fingers (Figure 1C): Turn the palm downwards. Clamp the person's finger back and press it from the root to the tip with the therapist's right hand. Finish the action by pulling the fingertip with the therapist's thumb and middle finger. Repeat the procedure for all fingers.

Step 4. Twisting fingers (Figure 1D): Twist the root, digital joint, and tip of the finger with the therapist's thumb and index finger. Repeat the procedure for all fingers.

Step 5. Shaking fingers (Figure 1E): Hold the person's fingertip, stretch it, then shake it lightly. Repeat the procedure for all fingers.

Step 6. Pulling out fingers (Figure 1F): Clamp the root of the person's finger and pull it out gently using the therapist's thumb and index finger. Repeat the procedure for all fingers.

Step 7. Springing fingers (Figure 1G): Clamp the person's fingertip using the therapist's thumb and index finger and open it rapidly. Repeat the procedure for all fingers.

Step 8. Turning the wrist (Figure 1H): Clamp the left forearm of the person and enable it to hang down naturally, then drive the wrist to shake with the arm.

Repeat Steps 1-8 for the right hands. 

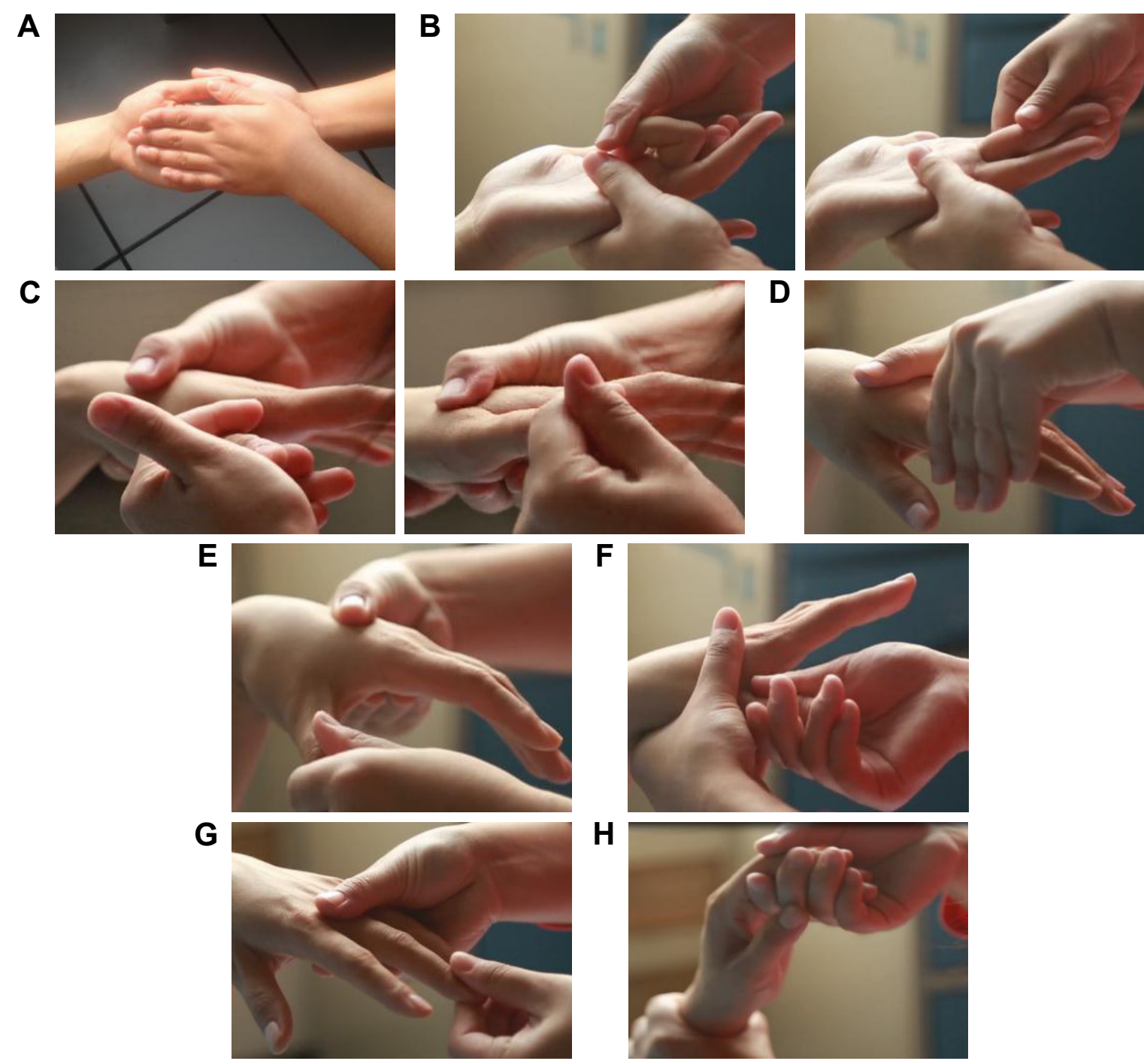

Figure I Passive exercises of finger motion. (A) warm up; (B) bending and stretching fingers; (C) pressing and pulling out fingers; (D) twisting fingers; (E) shaking fingers; (F) pulling out fingers; (G) springing fingers; and $(\mathbf{H})$ turning the wrist.

\section{Measurement}

Dietary intake has been found to affect the hand grip strength. ${ }^{26}$ Recently, Barrea et $\mathrm{al}^{27}$ have reported a positive association between adherence to the Mediterranean diet and muscle strength. Other factors, such as age, gender, and the anthropometric measurements including body mass index, muscle mass, and hand dimensions, can also affect hand grip strength. ${ }^{28}$ We assumed that these variables would not change much in a participant's 12 -week life in the natural setting of a residential aged care facility in the study period, therefore did not measure them for each participant.

Each participant's scores on grip strength and ADL were measured before and after 12 weeks of intervention. The grip strength was measured by electrical hand muscle dynamometer. ADL was measured by Barthel index (BI). All measurements were performed under strictly standardized conditions by the operator, using the same device and method described in the next section to avoid inter-observer and inter-device variability. The baseline data were collected from the personal health record in the facility, including age, gender, education, and marital status. The older people's subjective feelings about the intervention were asked in person.

\section{Grip strength}

$\mathrm{Lu}^{22}$ used a Camry-EH101 electrical hand muscle dynamometer (Henqi, Guangdong, China) to measure grip strength. We used the same dynamometer as they used. They first measured grip strength on 33 nursing students in our university. To ensure the validity of the results, they also measured grip strength by another dynamometer, Jian Ming grip strength dynamometer, which was commonly used for grip strength 
tests in China. As the measurement results acquired by the two dynamometers for the same person were similar, this validated the reliability of the equipment. Another reason for choosing to use this dynamometer was its measurement strength of up to $90 \mathrm{~kg}$, a fine resolution of $0.1 \mathrm{~kg}$ and calibration accuracy of $\pm 3 \%$. A grabbing distance of two grades were recommended for the participants to grip.

According to the recommendations of the American Society of Hand Therapists, ${ }^{29,30}$ in order to measure grip strength accurately, the participants should seat and place their feet on the floor naturally. The angle between knee and hip joints kept at $90^{\circ}$, shoulder adducted in neutral position, elbow flexed $90^{\circ}$, upper arm kept flat, forearm in a neutral position, and the wrist between $0^{\circ}$ and $30^{\circ}$ of dorsiflexion and $0^{\circ}$ and $15^{\circ}$ of ulnar deviation. ${ }^{29}$

After being provided with the information about the purpose and method of measurement, the participant was requested to hold the dynamometer. The grip strength was gradually increased to the maximum, then relaxed once the person could not maintain the force any more. The participant was then asked to rest by conducting simple movement to warm up the limb, then used the dynamometer again. After an adequate rest, the formal test started. Two tests were conducted and the scores recorded. The higher score was taken as the score of grip strength for the person.

\section{Ability to perform ADL}

The $\mathrm{BI}$ is a common scale used to measure performance in ADL. ${ }^{31,32}$ It uses ten variables describing ADL and mobility, including feeding, bathing, decorating, dressing, control of defecation, toilet utilization, transfer of beds and chairs, walking on ground and up- and downstairs. Bathing and decorating have two levels $(0,5)$; transfer of beds and chairs and walking on ground have four levels $(0,5,10,15)$. The remaining functions have three levels $(0,5,10)$. The total score is 100 . A higher BI score indicates a stronger capacity in performing ADL. All the items and the whole score in BI were adopted into the measurement scale for our study.

\section{Data analysis}

Data were collected before and after the intervention by two nursing students who were blinded to the purpose of the study. The data were recorded in a Microsoft Excel spreadsheet. SPSS v17.0 for Windows (Chinese version) was used for statistical analysis. The BI scores and grip strength were compared before and after intervention for each group, and between the intervention and control groups at two data points, before and after intervention.
As the data for grip strength and BI was continuous data, a $t$-test was used for comparison between groups if the data was normally distributed or by Mann-Whitney $U$-test other wise. Some baseline data were enumeration data, thus were compared using chi-squared test. $P<0.05$ was considered statistically significant.

\section{Results}

\section{Participant characteristics}

Forty older people with dementia met the eligibility criteria and were recruited into the experiment, 13 male and 27 female. At the end of the 12-week intervention, two participants in the experimental group withdrew from the study, citing domestic problems. Two participants in the control group left the institution and were lost to follow-up. As a result, 18 participants in each group completed the study.

Participants in both groups had similar demographics in terms of age, gender, educational level, marital status, presence of chronic disease, and level of severity in dementia (see Table 1). The average age of the participants was 80 years. There were five males and 13 females in the experimental group, seven males and 11 females in the control group. Of the participants in the experimental group, $61 \%$ had primary school education; whereas $50 \%$ of them in the control group were illiterate; $78 \%$ of the participants in the experimental group and $89 \%$ in the control group had other chronic diseases. The majority of participants $(77.8 \%)$ in each group were diagnosed with a moderate level of dementia. The remaining $22.2 \%$ in the experimental group and $16.7 \%$ in the control group were diagnosed with a mild level of dementia. The final 5.6\% of control group members had a severe level of dementia. In addition, the participants were provided with a similar nutritional diet by the residential aged care facility they lived in. They continued their usual medications, such as diabetes medicine or hypertension drugs.

\section{The effect of intervention on grip strength}

The mean score of grip strength was similar for both groups at baseline, 11.17 for the experimental group and 14.56 for the control group. The grip strength in both groups remained at a similar level to the baseline after the intervention; no significant difference was found between the two groups (see Table 2).

\section{The effect of intervention on ADL}

There was no significant difference in the baseline score for each of the ten variables measuring ADL between the intervention and the control groups (see Table 3). 
Table I Participant characteristics at baseline $(\mathrm{N}=36)$

\begin{tabular}{|c|c|c|c|c|}
\hline Characteristics & $\begin{array}{l}\text { Experimental group } \\
(\mathrm{n}=\mid \mathbf{8}) ; \mathrm{n}(\%)\end{array}$ & $\begin{array}{l}\text { Control group }(\mathrm{n}=18) \text {; } \\
\mathrm{n}(\%)\end{array}$ & $t / \chi^{2}$ & $P$-value \\
\hline Age (y), $\bar{X}(S D)$ & $80.72(7.29)$ & $79.72(9.43)$ & 0.36 & 0.72 \\
\hline \multicolumn{5}{|l|}{ Gender } \\
\hline Male & $5(27.80)$ & $7(38.90)$ & & 0.48 \\
\hline Female & $13(72.20)$ & $11(61.10)$ & & \\
\hline \multicolumn{5}{|l|}{ Education } \\
\hline Illiteracy & $5(27.80)$ & $9(50.00)$ & & 0.06 \\
\hline Primary school & II (6I.I0) & $4(22.20)$ & & \\
\hline Junior high & $2(11.10)$ & $5(27.80)$ & & \\
\hline$\geq$ Senior high & $0(0.00)$ & $0(0.00)$ & & \\
\hline \multicolumn{5}{|l|}{ Marital status } \\
\hline Unmarried & $2(11.10)$ & $3(16.70)$ & & 0.61 \\
\hline Married & $6(33.30)$ & $6(33.30)$ & & \\
\hline Divorced & $0(0.00)$ & I (5.60) & & \\
\hline Widowed & $10(55.60)$ & $8(44.40)$ & & \\
\hline \multicolumn{5}{|c|}{ Presence of chronic disease } \\
\hline No & $4(22.20)$ & $2(11.10)$ & & 0.66 \\
\hline Yes & $14(77.80)$ & $16(88.90)$ & & \\
\hline \multicolumn{5}{|l|}{ Dementia severity } \\
\hline Mild & $4(22.20)$ & $3(16.70)$ & & 0.57 \\
\hline Moderate & $14(77.80)$ & $14(77.80)$ & & \\
\hline Severe & $0(0.00)$ & I $(5.60)$ & & \\
\hline
\end{tabular}

Abbreviations: $y$, Years; SD, standard deviation.

For the intervention group, there was significant improvements in scores for two items and the overall ADL after the intervention. The score for urine control was significantly improved from the baseline of $6.94 \pm 3.04-9.44 \pm 1.62$ $(P<0.01)$; defecation control from the baseline of $7.50 \pm 2.57-8.89 \pm 2.14(P<0.05)$; and the overall BI score from the baseline of 71.39 $\pm 27.27-76.11 \pm 25.00(P<0.05)$. Conversely, there was a significant deterioration in overall ADL score in the control group, from the baseline of $74.17 \pm 27.02-67.22 \pm 31.02(P<0.05)$.

Although no significant change was detected, three ADL items in the intervention group showed a positive trend of improvement after the intervention; a trend that was not found in the control group. In the intervention group, the score for dressing improved from 6.11 $\pm 4.71-7.50 \pm 3.09$, toilet utilization from $7.78 \pm 3.92-8.06 \pm 3.04$, and walk on the ground from $12.22 \pm 5.75-12.78 \pm 4.92$.

Table 2 Grip strengths of experimental and control groups, $\bar{X}(\mathrm{SD})$

\begin{tabular}{l|l|l|l}
\hline Variables & $\begin{array}{l}\text { Experimental } \\
\text { group }\end{array}$ & $\begin{array}{l}\text { Control } \\
\text { group }\end{array}$ & $P$-value (t/z) \\
\hline Pre-intervention & II.I7 (6.37) & I4.56 (8.22) & $0.18(-1.38)$ \\
Post-intervention & II.03(5.25) & I4.47 (7.7I) & $0.13(-1.57)$ \\
$P$-value $(t / z)^{b}$ & $0.85(0.19)$ & $0.92(0.10)$ & \\
\hline
\end{tabular}

Notes: ${ }^{a}$ Between experimental and control groups. 'Between pre- and postintervention within each group.

Abbreviation: SD, standard deviation.
Only three items in the intervention group, feeding, decorating, and transfer of beds and chairs, showed a trend of deterioration after the intervention. Conversely, nine items showed a deteriorating trend in the control group. They were feeding, dressing, decorating, bathing, urine control, defecation control, transfer of beds and chairs, walk up and down stairs, and walk on the ground.

After the intervention, only one ADL item, urine control, was significantly better in the intervention group than in the control group. The scores for the remaining items remained similar between the two groups.

\section{Discussion}

Using the method of RCT, this study designed, implemented, and tested the effect of a set of simple and safe passive finger exercises on finger strength and ADLs for people with dementia.

\section{Passive finger exercises had no obvious influences on the grip strength of older people with dementia}

Grip strength is the gripping force of hands. It measures the performance of hand movements. Reducing grip strength can result in reduced hand functions, which may negatively impact on a person's ability to perform ADL. Therefore, grip strength can be considered an important index for the performance of ADL. 
Table 3 BI scores for both groups, $\bar{X}(S D)$

\begin{tabular}{|c|c|c|c|c|}
\hline Item & Timing & Experimental group & Control group & $P$-value $(t / z)^{a}$ \\
\hline \multirow[t]{3}{*}{$\mathrm{BI}$} & Pre-intervention & 71.39 (27.27) & $74.17(27.02)$ & $0.76(-0.3 I)$ \\
\hline & Post-intervention & $76.11(25.00)$ & $67.22(31.02)$ & $0.35(0.95)$ \\
\hline & $P$-value $(t / z)^{b}$ & $0.04^{c}(-2.27)$ & $0.01^{\mathrm{c}}(3.13)$ & \\
\hline \multirow[t]{3}{*}{ Feeding } & Pre-intervention & $7.22(3.52)$ & $6.67(2.97)$ & $0.48(-0.70)$ \\
\hline & Post-intervention & $6.94(3.04)$ & $5.56(2.92)$ & $0.16(-1.4 I)$ \\
\hline & $P$-value $(t / z)^{\mathrm{b}}$ & $0.66(-0.45)$ & $0.10(-1.63)$ & \\
\hline \multirow[t]{3}{*}{ Dressing } & Pre-intervention & $6.11(4.71)$ & $7.50(3.93)$ & $0.38(-0.87)$ \\
\hline & Post-intervention & 7.50 (3.09) & $6.39(4.47)$ & $0.57(-0.57)$ \\
\hline & $P$-value $(t / z)^{\mathrm{b}}$ & $0.06(-1.89)$ & $0.10(-1.63)$ & \\
\hline \multirow[t]{3}{*}{ Decorating } & Pre-intervention & $2.50(2.57)$ & $2.78(2.56)$ & $0.74(-0.33)$ \\
\hline & Post-intervention & $2.22(2.56)$ & $2.22(2.55)$ & $1.00(0.00)$ \\
\hline & $P$-value $(t / z)^{b}$ & $0.32(-1.00)$ & $0.16(-1.4 I)$ & \\
\hline \multirow[t]{3}{*}{ Toilet utilization } & Pre-intervention & $7.78(3.92)$ & $7.22(4.6 I)$ & $0.84(-0.20)$ \\
\hline & Post-intervention & $8.06(3.04)$ & $7.22(4.28)$ & $0.73(-0.34)$ \\
\hline & $P$-value $(t / z)^{b}$ & $0.56(-0.58)$ & $1.00(0.00)$ & \\
\hline \multirow[t]{3}{*}{ Bathing } & Pre-intervention & $0.83(1.92)$ & $0.56(1.62)$ & $0.64(-0.48)$ \\
\hline & Post-intervention & $0.83(1.92)$ & $0.28(1.18)$ & $0.30(-1.05)$ \\
\hline & $P$-value $(t / z)^{b}$ & $1.00(0.00)$ & $0.32(-1.00)$ & \\
\hline \multirow[t]{3}{*}{ Control urine } & Pre-intervention & $6.94(3.04)$ & $7.78(3.52)$ & $0.30(-1.04)$ \\
\hline & Post-intervention & $9.44(1.62)$ & $7.22(3.52)$ & $0.02^{\mathrm{c}}(-2.26)$ \\
\hline & $P$-value $(t / z)^{b}$ & $0.0 I^{c}(-2.7 I)$ & $0.48(-0.7 \mathrm{I})$ & \\
\hline \multirow[t]{3}{*}{ Defecation control } & Pre-intervention & $7.50(2.57)$ & $7.78(3.52)$ & $0.5 \mathrm{I}(-0.66)$ \\
\hline & Post-intervention & $8.89(2.14)$ & $7.50(3.54)$ & $0.22(-1.22)$ \\
\hline & $P$-value $(t / z)^{b}$ & $0.03^{c}(-2.24)$ & $0.7 \mathrm{I}(-0.38)$ & \\
\hline \multirow[t]{3}{*}{ Transfer of beds and chairs } & Pre-intervention & $13.89(2.14)$ & $13.89(2.14)$ & $1.00(0.00)$ \\
\hline & Post-intervention & $13.06(3.89)$ & $13.06(3.49)$ & $0.95(-0.06)$ \\
\hline & $P$-value $(t / z)^{b}$ & $0.26(-1.13)$ & $0.08(-1.73)$ & \\
\hline \multirow[t]{3}{*}{ Walk up and down stairs } & Pre-intervention & $6.39(4.47)$ & $7.22(3.92)$ & $0.60(-0.52)$ \\
\hline & Post-intervention & $6.39(4.47)$ & $6.39(4.13)$ & $0.93(-0.09)$ \\
\hline & $P$-value $(t / z)^{\mathrm{b}}$ & $1.00(0.00)$ & $0.08(-1.73)$ & \\
\hline \multirow[t]{3}{*}{ Walk on the ground } & Pre-intervention & $12.22(5.75)$ & $12.78(4.92)$ & $0.93(-0.09)$ \\
\hline & Post-intervention & I2.78 (4.92) & $11.39(6.37)$ & $0.62(-0.50)$ \\
\hline & $P$-value $(t / z)^{b}$ & $0.4 \mathrm{I}(-0.82)$ & $0.10(-1.63)$ & \\
\hline
\end{tabular}

Notes: aBetween experimental and control groups. ${ }^{b}$ Between pre- and post-intervention within each group. ${ }^{c P}$-value $<0.05$.

Abbreviations: SD, standard deviation; BI, Barthel index.

$\mathrm{Lu}^{22}$ administered a grip strength intervention on older people with a usual level of cognitive function in a nursing home for 3 months. Their intervention included finger flexibility exercises (active finger exercises) and finger force training, which included weight-lift training and pinching the grip ball every day. The interventions improved hand functions and grip strength. Different from their results, we did not find a significant improvement in grip strength after providing passive finger exercises to the people with dementia. The difference of our design from $\mathrm{Lu}^{22}$ was not providing finger lifting exercise and pinching the grip ball. Another difference was that our participants all suffered from dementia, thus their cognitive abilities were much worse than the normal older people in Lu's study. The length of our intervention period is 12 weeks, nearly 1 week shorter than that in Lu's study. Therefore, future interventions may consider including finger lifting exercise and pinching the grip ball, and re-tests if hand functions and grip strength improved.

\section{Passive finger exercises improved the urination control, defecation control, and overall ability of ADL for older people with dementia}

Two ADL items, urination control and defecation control, and the overall ADL score were significantly improved after the intervention. This provides support that the exercises designed in this study could promote continence of people with mild-to-moderate dementia. Several studies identified various benefits of finger exercises for ADL of people with dementia. ${ }^{18,19,21} \mathrm{Qu}$ et a ${ }^{18}$ found that 6-month finger exercises 
led to improvement in self-care and using tools in older people with mild dementia. Zhang et $\mathrm{al}^{21}$ found that 6-month sequential training comprising of finger exercises and ADL can improve the ability to perform ADL for people with dementia. A further study in 2016 generated the finding that finger exercises can effectively improve the daily self-care ability of people with mild dementia. ${ }^{19}$ There may be two explanations for this phenomenon: first, there is evidence that symptoms of incontinence can be effectively improved through psychological intervention of relaxation. ${ }^{33,34}$ When finger exercises draw a person's attention, it effectively induces psychological relaxation in the person. Second, continence is controlled by the brain. The reflex area of the brain is the inner side of the thumb. ${ }^{35}$ Therefore, massaging the thumb in finger exercises may stimulate the brain, the control center of continence, which, in turn, may lead to improvement in continence. Wang and $\mathrm{Kui}^{36}$ also suggested that these exercises can promote blood circulation to the brain and the central nervous system, thus improve brain function and lead to improvement in ADL. Likewise, our study adds evidence to support the benefits of finger exercises for improving ADL for people with mild-to-moderate dementia.

\section{Study limitations}

Due to a lack of follow-up observations, we could not ascertain the long-term effects of the finger exercises. As the entire study population was drawn from one residential aged care facility, the applicability of the finding is limited by the type of participants in the facility. Third, the participants in the experiment group received personal attention from the researcher in the process of the passive finger exercises. This personal attention could be a positive factor for improving the overall wellbeing of the participants. However, it is obvious that personal attention would not fully contribute to the improvement in two ADL items of urinary control and defecation function; therefore, the effect of the intervention must count.

We did not measure the changes in the factors that may influence grip strength, such as dietary intake, age, gender, body mass index, muscle mass, and hand dimensions, for each participant before and after the intervention, based on the assumption that these variables would change little in the 12-week study period. This can be a limitation to address in a future study. Finally, the small sample size made it impossible to compare the effect of the exercises on mild and moderate dementia.

Further studies and observations are, therefore, needed to confirm our results for different stages of disease progression, as well as to investigate the appropriateness of this intervention for older people with dementia in settings other than institutional care.

\section{Conclusion}

This study designed and administered a set of passive finger exercises for people with mild and moderate dementia. These exercises significantly improved these people's ability to control urine and defecation and the overall ADL. Therefore, this finger exercise can be considered for inclusion in the physical exercise programs for older people with mild or moderate dementia. Future study can focus on improving the design of the finger movement to achieve the aim of improving grip strength.

\section{Implications on dementia care}

Passive finger exercises are easy and safe and can improve function of urination and defecation control, and overall ADL for older people with mild and moderate dementia. This finding suggests that it is worthwhile to include these passive finger exercises into the physical exercise program for this population group.

\section{Acknowledgments}

This work was supported by an industry linkage grant provided by Hangzhou Government for Hangzhou Normal University Qianjiang College [2015] No 7. The study participants and their family members are acknowledged for participating in the study and agreed to undertake the relevant measurement. We are grateful for the support and help provided by the facility management and staff for the conduct of this project.

\section{Disclosure}

The authors report no conflicts of interest in this work.

\section{References}

1. World Health Organization [webpage on the Internet]. Dementia [updated February 21, 2018; cited April 9, 2018]. Available from: http://www. who.int/news-room/facts-in-pictures/detail/dementia. Accessed April 9, 2018.

2. Cummings JL, Morstorf T, Zhong K. Alzheimer's disease drugdevelopment pipeline: few candidates, frequent failures. Alzheimers Res Ther. 2014;6(4):37.

3. Fu WN, Liu QY, Chai Y, Liu B. Research progress of nursing on Alzheimer's disease in China. Chin J Soc Med. 2015;32(5):393-395.

4. Han JX. Handbook of Dementia: Diagnosis and Treatment of Integrated Medicine. 1st ed. Tianjin: Tianjin Science and Technology Translation Publishing Company; 2013.

5. Heßmann P, Seeberg G, Reese JP, et al. Health-Related Quality of Life in Patients with Alzheimer's Disease in Different German Health Care Settings. J Alzheimers Dis. 2016;51(2):545-561. 
6. Shinagawa S, Honda K, Kashibayashi T, Shigenobu K, Nakayama K, Ikeda M. Classifying eating-related problems among institutionalized people with dementia. Psychiatry Clin Neurosci. 2016;70(4): 175-181.

7. Byrne LM, Wilson PM, Bucks RS, Hughes AO, Wilcock GK. The sensitivity to change over time of the Bristol Activities of Daily Living Scale in Alzheimer's disease. Int J Geriatr Psychiatry. 2000;15(7): 656-661.

8. Lu YM, Chen XP. Progress of grip strength research. Health Research. 2011;31(4):306-308.

9. Zhou M, Wang X, Liu Z, et al. Advances of molecular imaging probes for the diagnosis of Alzheimer's disease. Curr Alzheimer Res. 2014;11(3):221-231.

10. Xiang Z, Tian DW. Effect of finger exercises on recovery of hand function and daily life ability in postoperative patients with bone trauma. Modern Clinical Nursing. 2016;15(7):8-10.

11. Hu ZJ, Luo Q, Lu XL, Peng XL. Explore the effect of hand exercises for patients with rheumatoid arthritis on the hand function. Chin J Women Child Health Res. 2016;27(S1):44-45.

12. Draganski B, Gaser C, Busch V, Schuierer G, Bogdahn U, May A. Neuroplasticity: changes in grey matter induced by training. Nature. 2004;427(6972):311-312.

13. Zheng LY. A Study on CBF of the Cortical Activation Induced by Simple Hand Motor in Normal Subjects by Use of SPECT [dissertation]. Jilin Jilin University Chinese; 2004.

14. Nyberg L, Eriksson J, Larsson A, Marklund P. Learning by doing versus learning by thinking: An fMRI study of motor and mental training. Neuropsychologia. 2006;44(5):711-717.

15. Bai X. The effect of hand exercises on students of mental retarded in the resources classrooms. Learning Weekly. 2016;0(3):28.

16. Bragin V, Bragin I. Feasibility of evidence-based hand exercises in a home-based program for patients with Alzheimer's disease and depression. Alzheimers Dementia. 2013;9(4):P117.

17. Geng QB. The effect of finger exercises training in elderly patients with mild cognitive impairment. Guide China Med. 2012;10(24): 488-489.

18. Qu Y, Zhang CH, Zhu HX. Finger exercises can improve the activities of daily living in elderly patients with mild dementia. Shanghai Nurs J. 2012;12(4):14-16

19. Zhang L, Qi F, Liu ZZ. Nursing effect of finger exercises on mild senile dementia patients. J Baotou Med Coll. 2016;32(9): 116-117.

20. Wu XM, Wu XS, Wang LL. Application effect of specialty nursing on treatment of elderly patients with mild or moderate Alzheimer's disease. J Clin Med Prac. 2016;20(8):21-23.
21. Zhang $\mathrm{CH}, \mathrm{Xu}$ Y, Zhu HX. The effect of sequential care on the ability of daily life for elders with moderate dementia. Shanghai Nurs J. 2010;10(1):30-33.

22. Lu YM. Survey and Intervention Study on the Oldest-Old's Grip Strength in Pension Agency [dissertation]. Hangzhou: Hangzhou Normal University, Chinese; 2012.

23. Lee HJ, Don Kim K. Effect of physical activity on cognition and daily living activities of the elderly with mild dementia. J Phys Ther Sci. 2018;30(3):428-433.

24. Wang FL. The Helsinki Declaration of the World Medical AssociationEthical Principles of Medical Research Involving Human Subjects. Chin Med Ethics. 2016;29(3):544-546.

25. Zhang LX, Liu XQ. Effect assessment on intervention of hands exercise for the patients with mild cognitive impairment disease. J Nurs Sci. 2008;23(2):61-62.

26. McLean RR, Mangano KM, Hannan MT, Kiel DP, Sahni S. Dietary Protein Intake Is Protective Against Loss of Grip Strength Among Older Adults in the Framingham Offspring Cohort. J Gerontol A Biol Sci Med Sci. 2016;71(3):356-361.

27. Barrea L, Muscogiuri G, Di Somma C, et al. Association between Mediterranean diet and hand grip strength in older adult women. Clin Nutr. In press 2018.

28. Su LQ, Yin ZX, Wang XC, et al. Study on handgrip strength of elderly $\geq 60$ years old from longevity areas in China. Zhonghua Yu Fang Yi Xue Za Zhi. 2017;51(11):1007-1011.

29. Hillman TE, Nunes QM, Hornby ST, et al. A practical posture for hand grip dynamometry in the clinical setting. Clin Nutr. 2005;24(2): 224-228.

30. Duan YJ, Wang NH. Advance in hand grip measurement. Chin J Rehabil Theory Prac. 2009;15(10):948-951. Chinese.

31. Mahoney FI, Barthel DW. Functional evaluation: the Barthel Index. Md State Med J. 1965;14:61-65.

32. Lin XL. Effects of Group-Activity on the Quality of Life of the Senile Dementia Patients [dissertation]. Shanghai: Fudan University; 2011. Chinese.

33. Li L. The treatment and nursing of urinary incontinence in the elderly. Shanxi Med J. 2014;43(18):2233-2236.

34. Hong HH, Wang YP. The effect of psychological nursing in the community elders with urinary incontinence. J Clin Med. 2017 4(17):3277-3278

35. Chen GC, Guo XB. Hand Reflex Area and Acupoint Massage Wall Chart. 1st ed. Fuzhou: Fujian Science and Technology Press; 2013.

36. Wang Y, Kui JZ. Application of acupoint massage in nursing care of elderly patients with dementia. Yunnan J Tradit Chin Med Mater Med. 2014;35(4):81-82.
Clinical Interventions in Aging

\section{Publish your work in this journal}

Clinical Interventions in Aging is an international, peer-reviewed journal focusing on evidence-based reports on the value or lack thereof of treatments intended to prevent or delay the onset of maladaptive correlates of aging in human beings. This journal is indexed on PubMed Central, MedLine,

\section{Dovepress}

CAS, Scopus and the Elsevier Bibliographic databases. The manuscript management system is completely online and includes a very quick and fair peer-review system, which is all easy to use. Visit http://www.dovepress. com/testimonials.php to read real quotes from published authors. 